\title{
Opportunity Cost Pass-through from Fossil Fuel Market Prices to Procurement Costs of the U.S. Power Producers
}

\author{
Yin Chu, Scott Holladay and Jacob LaRiviere
}

WORKING PAPER \#2017-02

\author{
WORKING PAPER SERIES \\ DEPARTMENT OF ECONOMICS \\ HASLAM COLLEGE OF BUSINESS \\ http://econ.bus.utk.edu
}

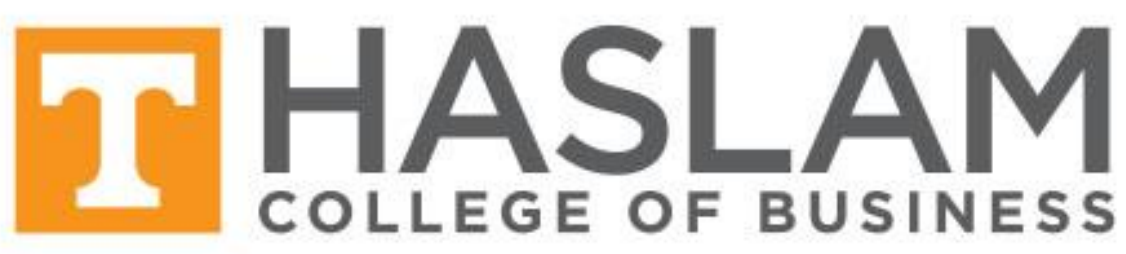

THE UNIVERSITY OF TENNESSEE, KNOXVILLE 


\title{
Opportunity Cost Pass-through from Fossil Fuel
}

\section{Market Prices to Procurement Costs of the U.S. Power Producers}

\author{
Yin $\mathrm{Chu}^{* 1}$, Scott Holladay ${ }^{\dagger 2}$, and Jacob LaRiviere ${ }^{\ddagger 3}$ \\ ${ }^{1}$ Zhongnan University of Economics and Law \\ ${ }^{2}$ University of Tennessee \\ ${ }^{3}$ University of Tennessee and Microsoft
}

August 2016

\begin{abstract}
This paper investigates the transmission of fossil fuel commodity spot market price changes to procurement costs of U.S. power producers. We measure and compare the speed and magnitude with which spot prices predict procurement costs using restricted access fuel price data. While natural gas spot prices are quickly reflected in procurement costs, coal spot prices offer very little predictive power to coal procurement costs. Although not causal, the empirical results also show differences across regulatory status and, for natural gas, price adjustment given positive and negative cost shocks. These findings may have implications for the electricity market deregulation literature that creates marginal cost curves as a competitive benchmark as there are significant differences in marginal cost curves constructed using spot versus the restricted receipt prices.
\end{abstract}

Keywords: electric power industry; fossil fuel market; pass-through; deregulation; asymmetric price adjustment

JEL Codes: D40, L51, L94

*182 Nanhu Avenue, Wuhan, Hubei 430073, P.R. China (email: yinchu@znufe.edu.cn)

${ }^{\dagger} 916$ Volunteer Blvd, Room 515, Knoxville, TN 37996, U.S. (email: jhollad3@utk.edu)

${ }^{\ddagger} 14820$ NE 36th St, Redmond, WA 98052, U.S. (email: jlariv@utk.edu). 


\section{Introduction}

For a variety of reasons including exposure to risk, incidence and methodological issues, cost pass-through receives broad attention in economics ((Weyl and Fabinger, 2013) $)$ ! In the energy sector, pass through receives particularly intense attention as both a transportation fuel $(($ Knittel et al., $2015 \mathrm{a}))$ and in the electric power industry (Zachmann and Von Hirschhausen (2008), Fell (2010), Fell et al. (2013), and Fabra and Reguant (2014)). The energy sector is particularly important because both households and firms budget for energy expenditures, which account for roughly $5 \%$ of GDP ${ }^{2}$

In this paper, we evaluate how fossil fuel procurement costs for U.S. electricity producers respond to fluctuations in fossil fuel spot market prices and whether those responses vary by fossil fuel type. We pay special attention to how quickly fossil fuel spot market price changes manifest in procurement costs paid by power plants. The drop in natural gas prices due to hydraulic fracturing makes this an important policy question: as more electricity is produced from natural gas, changes in the timing and completeness of spot prices manifesting as procurement costs could affect volatility of wholesale electricity prices, the efficiency of energy markets and in turn the wider economy. We are not aware of any previous studies devoted to this issue.

To address the question, we collected fuel procurement data from the U.S. Energy Information Administration (EIA) under a special agreement which gave us access to fuel procurement data for almost all fossil fuel power plants, both regulated and unregulated, in the United States for each shipment over a 11 year period from 2002-2012. We matched each power plant to fossil fuel spot market price data from Bloomberg Data Services. We then estimate auto-regressive models with different lag structures and fixed effects to identify to what extent power plants' purchase prices of coal, natural gas and oil reflect commodity spot prices.

Our methodology bears a strong resemblance to the traditional pass through literature described above, but the economic interpretation is different. (Weyl and Fabinger, 2013) show that pass through is a function of competition parameters so that "pass-through rates play an analogous role for imperfect competition to elasticities when competition is perfect." Rather than evaluating pass through and its welfare implications, we investigate how purchase prices of fossil fuel power plants reflect commodity spot prices. As a result, we refer to the particular type of pass through in our paper as "opportunity cost pass through" since the

\footnotetext{
${ }^{1}$ In international economics, there are a series of studies that investigate the transmission of exchange rate fluctuations to prices of imported goods (among others, see Goldberg and Knetter, 1997). The analysis of cost pass-through also provides important implications on the issue of tax incidence in public economics (Marion and Muehlegger, 2011) and price discrimination (Aguirre et al., 2010), merger assessment (Weyl and Fabinger, 2013), the incidence of anticompetitive firm behavior (Verboven and van Dijk |2009) and (Kim and Cotterill, 2008) in industrial organization.

${ }^{2}$ See http://www .eia.gov/totalenergy/data/annual/showtext.cfm?t=ptb0105
} 
opportunity cost of purchasing fuel inputs via a contract at any given point in time is the spot market price 3

Our main finding is that variation in the purchase price of natural gas closely follows variation in the spot price: "opportunity cost pass through" is both rapid and complete so that natural gas spot prices are a good proxy for power plant procurement costs. Conversely, coal spot prices are a poor proxy for coal purchase prices: for all types of coal, "opportunity cost pass through" is very slow and incomplete. Natural gas spot price fluctuations are reflected in fuel purchases almost completely within two months whereas contemporaneous and lagged coal spot prices do a poor job at predicting the coal purchase price. A $1 \%$ change in natural gas spot price leads to an approximately $0.85 \%$ change in the contract prices received by the power plants within 1 month. However, a $1 \%$ change in coal spot price leads to an approximately $0.11 \%$ change in the contract prices received by power plants even after 12 months. The implication is that coal spot prices are often a poor proxy for coal procurement costs.

There are several mechanical factors which could lead to estimating slower opportunity cost pass through for coal than natural gas. First, coal is more heterogeneous than natural gas which could lead to measurement error and attenuation bias. Our results are robust to both controlling for coal characteristics explicitly and estimating separate regressions for coal originating in different U.S. regions. Second, a mismatch between observed cost shocks and a firm's actual opportunity costs could be an issue (Nakamura and Zerom, 2010 Fabra and Reguant, 2014). Our use of EIA's propriety fuel cost data makes this less of a concern since we use actual purchase data. We describe the data and reporting requirements in detail below.

While we are not able to identify the underlying reason why coal spot prices might be a poor proxy for coal procurement costs using our research design, the results are consistent with conventional wisdom that coal is purchased via long term contracts. Conversely, natural gas is often purchased via the spot market since it is delivered by pipeline directly to power plants. Because our data contains some limited information on contract length, we are able to both control for contract type in our econometric model and trim the sample by contract lengths of different durations. In our sample, the majority of coal purchase contracts have a duration longer than one year. However, even when we restrict the sample to contain only the shortest length contracts explicitly listed in the sample- contracts less than one year- the result holds.

We also examine how procurement costs vary with spot prices under different regulatory and market circumstances. First, we compare opportunity cost pass through rates across regulated power plants and divested Independent Power Producers (IPPs). Previous literature on deregulation in the electric power industry documents evidence that divested power plants operated more efficiently under competition pressure. Specifically, deregulated coal-fired plants reduce procurement costs for coal relative to regulated plants

\footnotetext{
${ }^{3}$ We thank Glen Weyl for coining this term in informal conversation. Since we focus on opportunity cost pass through in an upstream market, previous related work by Adachi and Ebina (2014) might use the term "wholesale opportunity cost pass through".
} 
(Chan et al. 2013, Cicala, 2015, Jha, 2015). A related question is whether procurement costs differentially reflect commodity spot prices by regulatory status. For natural gas purchases, we find evidence that the transmission of fossil fuel spot prices to power producers' procurement costs is significantly faster in deregulated power plants than regulated power plants. In contrast, we do not find any significant differences in the opportunity cost pass-through pattern across regulatory status for coal purchases. We attempt to control for geography and the deregulation decision by adding data from before the major episodes of deregulation in 2001. These results are consistent with post-2003 data, opportunity cost pass through is faster in deregulated markets. Still, we do not claim to identify a causal relationship for reasons we describe below.

Finally, we analyze whether opportunity cost pass-through varies given an increase in market price versus a decrease. Asymmetric price adjustment has been empirically documented in a number of commodity markets (Peltzman, 2000), particularly in the fuel market (Borenstein et al. 1997) 4 We find that natural gas price decreases opportunity cost pass through to procurement prices more quickly than price increases. This is consistent with strategic behavior on the part of natural gas plants who draw down inventories during high price episodes. While we find no such effect for coal, we view this strictly as further evidence that spot prices are bad predictors of coal purchase prices in general. We do not view this as evidence, for example, that a tax on the production of coal would never be passed through to coal fired power plants and subsequent electricity prices. Our study uses only high frequency price variation and therefore the results are not externally valid to the type of low frequency price variation induced by tax changes. How a tax change would affect coal prices in the long run is an interesting and important question, but not the focus of our paper 5

Our results are relevant to both economists and policy makers ${ }^{6}$ First, natural gas plays an increasing role in the fuel mix for electricity generation due to lower prices attributable to hydraulic fracturing (Hausman and Kellogg (2015)). Rapid and complete natural gas opportunity cost pass through implies larger proportion of procurement costs in the electricity sector will reflect commodity spot prices. Procurement costs reflecting commodity spot prices also implies that any market volatility in natural gas prices will pass through to electricity producers and potentially electricity consumers quickly. This may expose electricity consumers

\footnotetext{
${ }^{4}$ For analyses in the electricity market, Zachmann and Von Hirschhausen (2008) first raised the puzzle of an asymmetric pass-through from European Union's $\mathrm{CO}_{2}$ emission prices to wholesale electricity prices. Mokinski and Wölfing (2014) document empirical evidence of asymmetric adjustment of wholesale electricity prices in response to $\mathrm{CO}_{2}$ emission prices.

${ }^{5}$ Long lived price changes, like taxes, have been shown to affect coal purchase quantities, for example, Kolstad and Wolak Jr (1983). Because we use monthly variation in market prices, we do not view our findings as robust to discrete and long lived tax policy changes. We focus exclusively on procurement costs as the dependent variable of interest and leave the effects of spot price changes on quantities to future work.

${ }^{6}$ In the appendix we demonstrate the potential methodological importance of these results. We construct alternative marginal cost curves for two deregulated electric power markets. Using reported spot prices versus actual fuel costs changes the dispatch order significantly.
} 
to greater electricity price volatility. Sticky coal procurement costs mitigated this historically.

Second, we document evidence that there are distinct pass-through patterns from fossil fuel spot prices to procurement costs by regulatory status. Opportunity cost pass through is faster for deregulated power plants for natural gas purchases. This is consistent with previous findings that deregulation affects the fossil fuel purchase behaviors of power plants (Chan et al., 2013, Cicala, 2015, Jha, 2015). However, our findings are not sufficient to make causal inference since even with cross-sectional variation in regulatory status with pre-2001 data the decision to deregulate is likely endogenous. It does, though, provide further evidence that deregulated firms operate very differently than regulated firms. A more complete theoretical model of pass through would be needed to determine the welfare effects of these differences.

There are a couple a caveats to our study. First, we test for differences in commodity market pass through to fossil fuel procurement of electricity producers. The more important question from a welfare perspective is how fossil fuel prices are passed through to electricity prices. Data limitations on the bidding behavior of generators restrict our ability to address the electricity pricing question 7 Second, we estimate differences in opportunity cost pass through by regulatory status rather than the causal impact of deregulation on pass through. As a result, our regulatory results are merely suggestive. Similarly, we do not have an instrument to identify the causal impact of commodity price increases or decreases on fuel procurement costs. The goal of our paper is simply to document differences in opportunity cost pass through behavior between coal and natural gas power producers. Third, insofar as procurement contract differences are the best explanation of our findings, the deeper economic question at the root of our result is why coal and natural gas are purchased with contracts of different lengths. Earlier work points out that contract type can be a function of relationship specific investments (Masten and Crocker (1985) and Joskow (1987)). As a result, it could be that "opportunity cost pass through" is a function of competition parameters which dictate the timing and nature of these relationship specific investments. Finally, our identification strategy is based on month-tomonth variation in fuel prices. For that reason, our estimated opportunity cost pass through rates are not predictive of the impacts of long-run changes in fossil fuel prices driven by taxes from carbon policy or new extractive technologies such as fracking 8

The paper proceeds as follows. Section 2 describes the context of the analysis. Section 3 describes the data and summary statistics. In Section 4, we present the baseline empirical model. In Section 5, we provide the empirical results and the discussion. Section 6 concludes.

\footnotetext{
${ }^{7}$ In Fabra and Reguant (2014), the authors develop a structural model and detailed data on generators supply decisions to estimate pass through in the presence of strategic bidding. While some electricity markets publish bid data from electric generators, those bids are typically masked making it impossible to match bids with our fuel cost data.

${ }^{8}$ For example, it is likely that a carbon policy that taxes coal at the mine mouth would eventually pass through to coal fired power plants despite the fact we find no evidence of opportunity cost pass through from monthly variation in coal prices. Our results do suggest that the pass through would likely be gradual.
} 


\section{Context}

\subsection{Contract Duration of Different Fossil Fuels}

The duration of fossil fuel contracts between the power producers and suppliers is a key factor affecting fuel substitution in the generation mix in the electric power sector given fuel spot price shocks OECD/IEA, 2013). There are significant differences in contract duration between the coal and natural gas markets in the U.S. The coal market is characterized by long contracts: the median contract averages around 2 years in 2014 (Matisoff et al. 2014); 93\% of coal consumed for electricity generation in the U.S. was purchased via long-term contracts of more than a year (rather than spot contracts) in 2011 (EIA, 2012a). In contrast, the standard contract in the natural gas market is much shorter. In 2011, 66\% of natural gas consumed for electricity generation in the U.S. was purchased via spot contract (EIA, 2012a). Shorter natural gas contract lengths are potentially due to its wider use across different sectors although several other explanations like extant natural gas pipeline infrastructure are feasible (Petrash, 2006).

\subsection{Measuring Pass-through to Wholesale Electricity Prices}

Most previous literature of cost pass-through in the electricity market focuses on the transmission of input price shocks (e.g., emission allowance price variations) to wholesale electricity prices. Rather than looking at input price pass through to wholesale electricity price, we look at how commodity spot prices relate to procurement costs.

There are a couple reasons for focusing on the relationship between commodity spot prices and fuel procurement costs rather than wholesale electricity prices. First, for traditional regulated electricity markets, wholesale electricity transactions are realized via bilateral trading where market price determination mechanism is opaque. Also it is unclear what regulators use as marginal cost estimates for wholesale transactions between regulated utilities. Second, for restructured markets, the wholesale price is determined by bidding in multi-unit auctions. Measuring bidding behavior response by the marginal generating unit to changes in its marginal costs (e.g., fluctuations of fossil fuel procurement costs) is challenging because a firm's optimal bidding behavior depends not only on fossil fuel price shocks, but also the strategic adjustment of markups (Wolfram (1998); Borenstein et al. (2002); Hortacsu and Puller (2008); and Fabra and Reguant (2014)). These strategic incentives are likely to change with market conditions.

More precisely, in the case of deregulated power plants, in order to cleanly identify the pass-through from fossil fuel price changes to wholesale electricity prices, economists must tease out the contribution of strategic adjustment of markups and separate it from fuel costs. The previous literature derives the markup of a utility firm from the first-order condition of profit maximization, which depends on the net quantity 
sold (i.e., its production minus its vertical commitment), and the slope of the residual demand faced by the firm. The general approach of the previous literature is calculating the former by subtracting the firm's output by purchases from its subsidiaries, and approximating the latter based on the bid data. While data on generator bids exist for some deregulated markets they are typically masked so that we cannot match it to our input cost.

For all of these reasons, we focus on the pass-through between fossil fuel market prices and procurement costs of power plants. Using this metric gives us a direct measure of opportunity cost pass through mitigating any strategic factors in deregulated markets or any missing variables issues in regulated markets. It allows us to answer our primary question of interest in this paper: how does speed and completeness of opportunity cost pass through vary by fossil fuel type and regulatory status?

\section{Data}

\subsection{Data Description}

The study mainly exploits three separate data sets: (1) spot market prices of fossil fuels; (2) plant-level fossil fuel receipt cost data for electricity producers; and (3) cost estimates of railway transportation, during the period of 2002 to 2012 .

The first data set is mainly collected from Bloomberg. From the Bloomberg data, we obtain daily spot and future prices for natural gas at several hubs and weekly spot prices for coal extracted in three major deposits in the U.S.: the Powder River Basin, the Illinois Basin and the Central Appalachian (PRB, Illinois and CAPP). We aggregate the daily and weekly market prices to monthly averages to be consistent with the frequency of the fossil fuel receipt cost data. Boloomberg's market data is collected from dealers in the over-the counter market for coal. While relatively little coal transacts in the spot market, as little as $1 \%$ according to EIA, some power plants market their coal reserves to market using spot prices making these prices an appropriate measure of the opportunity cost that generators face, see EIA $(2012 \mathrm{~b}) .9$

The main source for the second data set is the records of FERC-423 and EIA-423 data forms called the "Monthly Report of Cost and Quality of Fuels of Electric Power Plants". FERC-423 form must be filed by all utility electricity-generating plants with a capacity of at least 50 megawatts, while EIA-423 is designated for the non-utility counterparts with capacity above the same cutoff. After 2008, both forms were incorporated in the survey Form EIA-923. The non-utility part of the data is not publicly available for privacy protection

\footnotetext{
${ }^{9}$ We also collect coal market spot prices from SNL energy, which collects data from a survey of market participants. There two price series are highly correlated, with correlation coefficients of 0.86 for PRB coal and 0.95 for Central Appalachian coal. Because the SNL data does not include Illinois coal and has a shorter time span for the other basins we employ the Bloomberg data in our analysis.
} 
purpose. We requested the proprietary data from EIA by signing a non-disclosure agreement which permits us to use the data for this high level analysis.

The proprietary transaction-level data contains purchased fossil fuel types and includes sub-fuel categories (e.g., bituminous coal), contract prices (including transportation costs and taxes), quantity of fuel delivered, average heat content of the fossil fuel, contract terms (e.g., contract type and in some cases, expiration date), average sulfur and ash content of coal, location of the purchasing plant and the origin of all coal shipments 10 Coal origin allows us categorize the coal transactions by coal type and thus match each procurement contract with the associated coal market price (PRB, CAPP or Illinois) from Bloomberg. We match natural gas purchases to the nearest trading hubs based on major transportation flow pattern of the U.S. Natural Gas market ${ }^{11}$ We match fossil fuel spot prices at Waha Hub (TX) for plants in NE and KS, prices at Opal Hub (WY) for plants in UT, WY and CO, prices at Blanco Hub (NM) for plants in AZ and NM, prices at Chicago Hub for plants in WI and IL, and prices at AECO Hub (Canada) for plants in IA, MN, ND, MT, WA, OR and NV, and prices at Henry Hub (LA) for the remaining plants.

Electric power plants with a capacity above $50 \mathrm{MW}$ are required to complete monthly reports on their operations under the Federal Energy Administration Act of 1974. Failing to report or knowingly submitting false reports is a criminal offense. The data for utility and non-utility providers are both taken from the same survey and prepared for release in the same way. EIA (2010) and EIA (2012a) provide a succinct description of how the data is collected, compiled and reported. Fuel cost data collected from these EIA surveys has been employed in several papers in the related literature, including Busse and Keohane (2007), Hortacsu and Puller (2008), Maria et al. (2014) and Cicala (2015) among many others ${ }^{12}$

Our third dataset controls for the costs of shipping coal via rail. Our fuel procurement cost data includes transportation delivery costs for coal. According to EIA reports, railroad is the main transportation mode for coal delivered to electric power plants (over 70\% in 2010). Rail transportation costs account for a sizable share of the total delivered cost of coal for electric power producers and vary across shipments of coal originating from different coal basins 13 If correlated with changes in coal prices, unobserved changes in rail transportation rates would bias the estimated results on the pass-through from coal market prices.

The EIA estimates that the costs of transporting coal to power plants rose by $46 \%$ nationally from $\$ 11.83$

\footnotetext{
${ }^{10}$ The contract types are divided into "spot" deliveries (for contracts that expire in less than one year), and "contract" deliveries (for longer-duration contracts). Expiration dates are available for "contract" deliveries, although this information is missing for many "contract" observations.

${ }^{11}$ See the map available from EIA: http://www.eia.gov/pub/oil_gas/natural_gas/analysis_publications/ ngpipeline/MarketCenterHubsMap.html.

${ }^{12}$ See also Fell et al. (2014), Knittel et al. $(2015 b)$, Jha $(2015)$ and Jha and Muller $(2016)$.

${ }^{13}$ EIA reports that during 2001-2008, the national average share of rail transportation cost as percent of total coal delivered costs is $20 \%$. The number could reach as high as $59 \%$ for shipments of coal originating in Powder River Basin. See more details on EIA reports available at http://www.eia.gov/coal/transportationrates/archive/2010/trendcoal.cfm.
} 


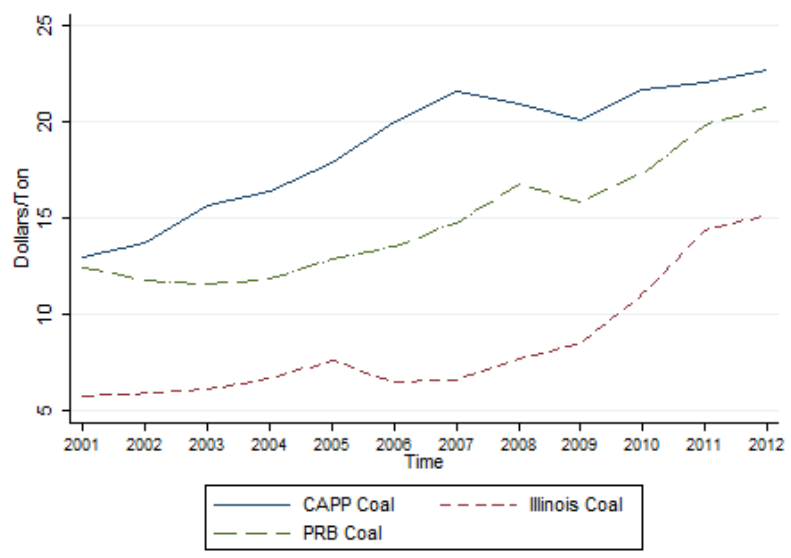

Figure 1: Rail Transportation Costs for Coal, by Mining Basins

Note: 2001-2007 data is based on the Surface Transportation Board (STB)'s 900-Byte Carload Waybill Sample. 2008-2012 data is calculated by EIA, which augmented STB's Waybill sample by EIA-923 Power Plant Operations Report data.

to $\$ 17.25$ per ton from 2001-2012. Figure1 shows the estimated rail transportation costs for coal originating from three major coal deposit basins we analyze in this paper. There are substantial increases in the rail delivery costs for coals from all 3 basins. During the same time, the demand for PRB coal increased due to environmental regulation and the lower sulfur content of PRB coal.

We are not aware of any dataset which specifically reports coal transportation costs so in order to handle this issue, we combine two data sets to approximate the changes in railroad transportation costs. The first data set is the EIA-estimated rail transportation cost data $(\$ /$ ton), which is available on yearly basis, and provides detailed information about deliveries from each coal basin to each state destination. For some deliveries, the data is proprietary to protect trade secrets. For those deliveries we use the average costs of deliveries from the same basin for proxies.

The second data set is the Rail Cost Adjustment Factor (RCAF) used in Busse and Keohane (2007). The RCAF is a national cost index computed quarterly by the Association of American Railroads to measure the rate of inflation in railroad inputs such as labor and fuel. It is also adjusted for productivity gains. The cost index is used by Surface Transportation Board to assess railroad rates. We transform the yearly data from EIA to quarterly data based on the quarterly deviation of Rail Cost Adjustment Factor as the share of the yearly average. Specifically, we applying the following formula to our data:

$$
\text { Rail Cost }_{y, q}=\text { Rail Cost }_{y}+\frac{R C A F_{y, q}-\frac{1}{4} \sum_{q=1}^{4} R C A F_{y, q}}{\frac{1}{4} \sum_{q=1}^{4} R C A F_{y, q}} * \text { Rail Cost }_{y}
$$

where $y$ is a specific year, $q$ is a quarter of year, $R C A F$ is the Rail Cost Adjustment Factor. We then assume 
within the same quarter, the rail transportation costs for coal deliveries to power plants grow at a constant rate. This interpolated proxy gives us the ability to calculate a monthly time series for rail delivery costs for coal.

Finally, we exploit the North American Industry Classification System Code (NAICS) information available from the records of the EIA-906 data form (also incorporated in EIA-923 after 2008 ), "Annual Electric Utility Data", to restrict the sample to electricity-generating plants in the electric power industry only. We further take advantage of the EIA Sector Code to identify plants that are divested non-utility Independent Power Producers (IPPs) and those that are regulated electric utility producers $\sqrt{14}$

Table 1: Summary Statistics

\begin{tabular}{rcccccc}
\hline \hline & Unit & Mean & Std. Dev. & Min. & Max. & Obs. \\
\hline Receipt Prices for Power Plants & & & & & & \\
PRB Coal & Cents/MMBtu & 154.7 & 58.7 & 12 & 957.5 & 58064 \\
CAPP Coal & Cents/MMBtu & 249.1 & 102.6 & 5.9 & 1074.4 & 83632 \\
IL Coal & Cents/MMBtu & 198.2 & 78.2 & 31.8 & 640 & 21413 \\
NG & Cents/MMBtu & 600.7 & 250.6 & 0.4 & 1768.1 & 177126 \\
\hline & & & & & & \\
Fossil Fuel Spot Market Prices & & & & & \\
PRB Coal & Cents/MMBtu & 57.3 & 18.8 & 30.6 & 117.9 & 132 \\
CAPP Coal & Cents/MMBtu & 236.5 & 80 & 111.6 & 511.3 & 132 \\
IL Coal & Cents/MMBtu & 174.5 & 51.9 & 103.2 & 348.2 & 132 \\
NG (Henry Hub) & Cents/MMBtu & 556.7 & 232.6 & 194.5 & 1342.4 & 132 \\
\hline & & & & & & \\
Rail Transportation Cost & Dollars/Ton & 15 & 5.6 & 2.4 & 41.5 & 10119 \\
\hline \hline
\end{tabular}

Note: The summary table is based on data from 2002 to 2012. For some natural gas purchases with very small volumes the receipt price is extremely high. Here we present statistics for natural gas receipt prices below the 99 th percentile.

\subsection{Summary Statistics}

Table 1 shows summary statistics for our data. There are non-trivial differences between the averages of fossil fuel spot market prices and the receipt procurement costs paid by power producers. The mean fossil fuel spot market prices are lower than costs for every fuel type. Highlighting the importance of transportation costs, though, the relative price differences are larger for coal compared to natural gas. Among the three types of coal, the mean fossil fuel spot market price of the PRB coal accounts for roughly $40 \%$ of the delivery price. This is consistent with relative clean PRB coal being shipped to east coast power plants subject to stricter environmental regulation on air pollution emissions.

To get a sense of dynamics in the data, Figure 2 plots changes in fossil fuel prices over time. Panel (a) displays fluctuations in fossil fuel spot market prices across time. The panel shows that the fossil fuel

\footnotetext{
${ }^{14}$ We exclude IPPs which are also co-generators with business purpose of heating.
} 
spot market price of PRB coal was less volatile than other fuel types. Given that market prices are jointly determined by supply, demand and substitutes, we are agnostic about the causes of this difference. We do note that all prices appear to be positively correlated to some extent.

Panels (b) and (c) highlight how procurement costs for coal fired power plants in two different parts of the country changed over our sample period. Transactions made by power plants near the relevant coal mining basins are selected to be compared with the regional coal spot market prices. We choose two states, Colorado and West Virginia, to highlight how receipt prices for PRB and CAPP coal, evolved over the sample period ${ }^{15}$ Panel (b) shows average procurement costs of PRB coal for coal plants in Colorado and panel (c) shows procurement costs of CAPP coal for coal plants in West Virginia. For both locations coal procurement costs display a consistent upward trend. For CAPP coal, procurement costs lack the high frequency volatility in the coal spot market prices. For PRB coal, procurement costs increase despite relatively flat PRB coal prices in the spot market. Panel (d) shows average procurement costs for natural gas delivered to New York power plants. These prices appear to track the level and volatility of the natural gas spot prices at Henry Hub. Despite not controlling for rail transport prices for coal, the graphs appear consistent with rapid natural gas opportunity cost pass through and slow coal price opportunity cost pass through.

\section{Empirical Strategy}

This study focuses on measuring how fossil fuel spot market prices manifest in fuel procurement costs in the electricity sector. To do so we use a reduced form econometric approach. While, we do not claim to identify causal impacts nor identify the underlying mechanisms behind our findings, we explore possible channels through which opportunity cost pass through could vary below.

In order to understand how changes in fossil fuel spot prices are transmitted to power producer procurement prices, we apply a common empirical model from the pass-through literature on exchange rate in international economics ${ }^{16}$ Those models are intended to determine how quickly exchange rate fluctuations are passed through to market prices of traded goods. That approach is well-suited to handle our setting if each individual power producing company cannot influence the market commodity price of each type of fossil fuel individually. It does allow, though, for demand across power producing firms to be correlated.

Our econometric specification takes the following form:

$$
\Delta \log \left(\text { Fuel Price } e_{i t}^{f}\right)=\alpha+\sum_{k=1}^{12} \beta_{k}^{f} \cdot \Delta \log \left(\text { Spot Price }_{t-k}^{f}\right) \cdot 1\left[\text { Fuel }_{f}\right]+\Psi \cdot X+\epsilon_{i t}^{f} .
$$

\footnotetext{
${ }^{15}$ Based on EIA's fuel purchase data for power plants, PRB coal made up $54 \%$ of total consumption in Colorado, and CAPP coal made up $23 \%$ of total coal consumption in West Virginia during the sample period.

${ }^{16}$ See Campa and Goldberg (2005), Nakamura and Zerom (2010) and Goldberg and Campa (2010) for examples.
} 


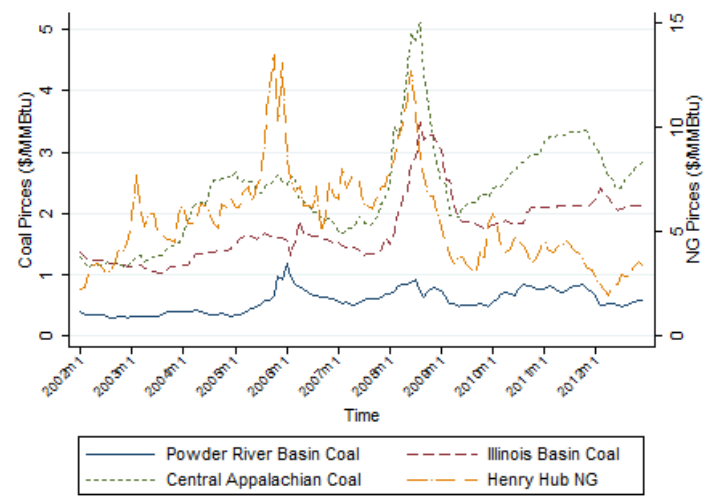

(a) Fossil Fuel Spot Market Prices

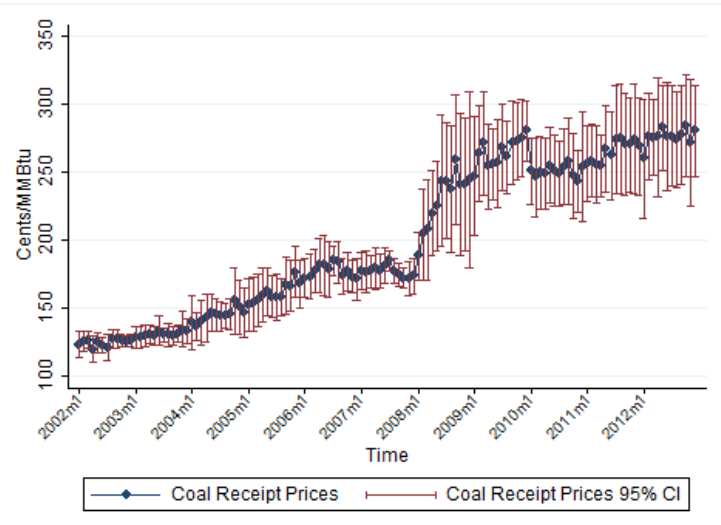

(c) Average Coal Delivered Receipt Costs in West Virginia

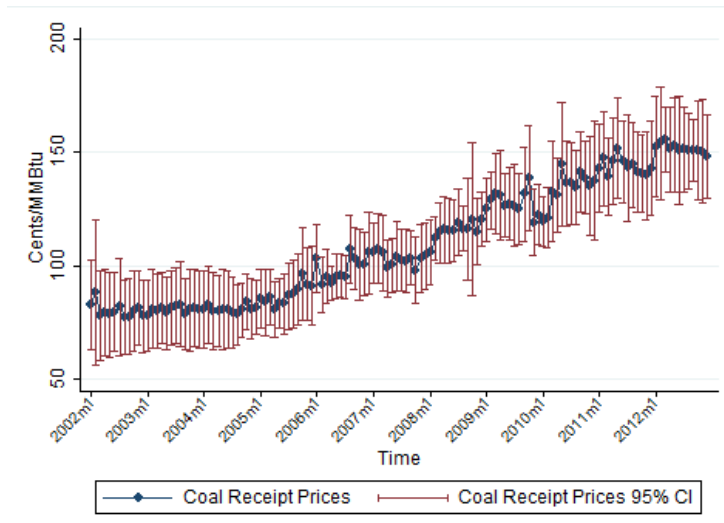

(b) Average Coal Delivered Receipt Costs in Colorado

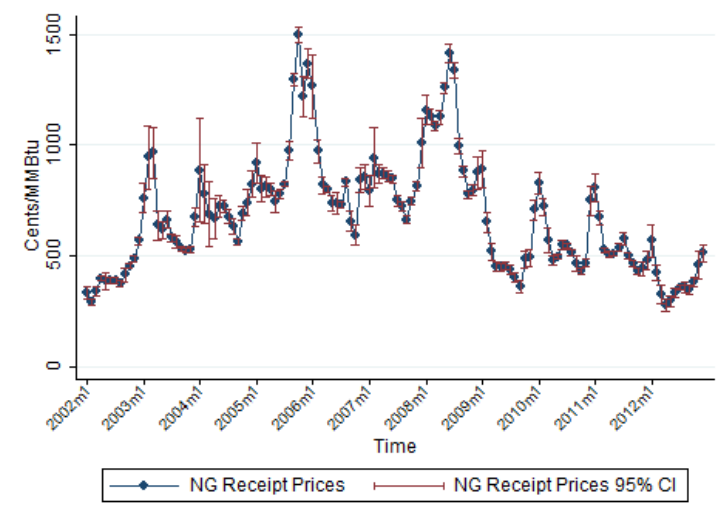

(d) Average NG Delivered Receipt Costs in New York State

Figure 2: Fossil Fuel Spot Market Prices and Delivered Receipt Costs for Power Plants

Note: the average fossil fuel delivered costs for power plants is weighted by transaction volume. PRB Coal purchases for plants in Colorado are selected to represent those for the PRB coal. CAPP Coal purchases for plants in West Virginia are selected to represent those for the CAPP coal. Fossil fuel receipt prices for power plants also include delivery costs. Panels b-d report the coefficients and 95\% confidence intervals from a regression of fossil fuel prices on month of sample dummies. They recover the average cost and a measure of the variance of the cost across plants in the state that use that fuel. 
In equation (2), for coal, $i$ indexes a plant-origin combination; for natural gas, $i$ indexes a power plant ${ }^{17}$ $t$ represents unique time periods, $f$ is a specific type of fossil fuel (coal or natural gas) and $1\left[F_{u e l}\right]$ is an indicator variable for each fuel. The term $\Delta$ represents first difference transformations, $\log \left(\right.$ FuelPrice $\left._{i t}^{f}\right)$ is the $\log$ of mean delivered cost of fuel in month $t, \log \left(\right.$ SpotPrice $\left._{t-k}^{f}\right)$ is the log spot market price for fuel $f$ lagged $k=1, \ldots, 12$ months. $X$ is a vector of control variables. We add lagged fossil fuel spot prices to allow for the possibility of gradual adjustment of power plants' procurement costs to fossil fuel spot prices, especially given the contract duration terms discussed in Section 2.1 $18 \beta_{k}^{f}$ is the coefficient of interest, which measures the percentage change in receipt prices of fuel $f$ associated with a one percentage change in the corresponding fossil fuel spot market prices $k$ months ago. The cumulative sum of the coefficients, $\sum_{k=0}^{12} \beta_{k}$, is then defined to be the aggregate long-run pass-through rate. The coefficients are identified off variation in changes of fuel spot prices within a plant-fuel-origin combination or a power plant differencing out the average effect for each month.

Our price variables are highly persistent: Dickey-Fuller tests for the hypothesis of a unit root in fossil fuel spot prices cannot be rejected at a $5 \%$ significance level ${ }^{19}$ Estimating the model in levels is problematic as a result. Therefore, we follow Campa and Goldberg (2005), Nakamura and Zerom (2010) and Goldberg and Campa (2010), by taking the first difference of both the right and left hand side price variables ${ }^{20}$

In addition to fossil fuel spot prices, we also control for other variables in $X$, including month-of-year fixed effects, change in log rail transportation costs ${ }^{21}$ and plant fixed effects ${ }^{22}$ We estimate the model using the data described in Section 3, for monthly changes in procurement costs and fossil fuel spot market prices over the 2002 - 2012 sample period. The standard errors are clustered at the plant level to allow for arbitrary serial correlation 23

In line with previous studies in the exchange rate pass-through literature where firms take exchange rates as given when pricing goods, the necessary assumption required in the current specification is that power

\footnotetext{
${ }^{17}$ For coal purchases, a coal-origin combination means transactions from an extraction type of coal mine (surface/underground mining) from a delivery county to a power plant.

${ }^{18}$ Most plants in our sample receive at least one delivery a month, ensuring that we have a fuel price observation. Around $9 \%$ of coal plants receive a single delivery per year. They are excluded from the analysis.

${ }^{19}$ We were unable to reject the hypothesis that the series of coal prices at the 3 mining basins or natural gas prices at various hubs were nonstationary. The Dickey-Fuller unit root test on the fuel spot prices in an econometric specification with a time trend rejects the unit root hypothesis only in natural gas prices at Chicago Hub.

${ }^{20}$ Coal characteristics should be constant at each coal origin. Thus, since the data for coal purchases are at the plant-origin level, coal characteristics should automatically drop off the equation after a first-difference transformation is applied if coal characteristics only affect the level of procurement costs.

${ }^{21} \mathrm{Log}$ rail transportation costs are set to zero for natural gas and for coal plants that are not matched with the estimated rail cost data from EIA. These plants are served via transportation mode other than railroads, such as barge or truck.

${ }^{22}$ For robustness checks, we also include coal characteristics such as ash content, heat content, sulfur content, a dummy variable for out of state coal and an indicator of coal mine type in levels to the first differences in prices.

${ }^{23}$ We were not able to reject the null hypothesis of no first order autocorrelation under the Wooldridge test for autocorrelation in panel data (Wooldridge, 2010).
} 
plants are price takers in the fossil fuel spot markets. We argue that this is a valid assumption given the fact that the fossil fuel spot markets are all large with many participants from diverse sectors such that no single power plant (or a power plant owning firm) has the market power to manipulate their fuel spot prices. Although individual plants or firms can engage in bilateral contracting with the fuel suppliers instead of (or in addition to) purchasing via fossil fuel spot markets, we argue this would not grant them the power to manipulate the fossil fuel spot market prices since input sellers always have the opportunity to sell at spot or futures prices. This type of empirical model has also been applied in previous studies with detailed panel data similar to ours 24

\section{Empirical Results}

In this section we present empirical results describing opportunity cost pass through by fuel type, by contract duration, regulatory status and across price increases versus decreases.

\subsection{Main Results}

This section describes the results from estimating equation (2) for coal and natural gas 25 Rather than display our results with a table of 12 coefficients per fuel type, we display our results graphically in Figure 3. Each fuel-specific line connects a month specific point estimate and bars represent the $95 \%$ confidence intervals for that month's point estimate. The pass-through pattern of coal is distinct from natural gas. Spot market price changes for natural gas quickly pass through to delivered contract costs for natural gas fired power plants. The pass-through responses occur almost entirely in the month of the price change and the subsequent month. The sum of the point estimates for the first two periods is approximately 0.81 with a standard error calculated using the delta method of 0.02 . The interpretation of this result is that a $1 \%$ increase in natural gas spot market price leads to an expected increase of $0.81 \%$ in procurement costs of natural gas by electricity producers within 2 months.

In contrast, pass-through is much more sluggish and far less complete for coal transactions. For coal, after 12 months the sum of all monthly coefficients is only 0.08 with a standard error of 0.01 . This implies a $1 \%$ increase in coal spot market price leads to only a $0.08 \%$ increase in the contract prices paid by power plants even after an entire year. Since average coal contracts in the U.S. last for approximately 2 years, we

\footnotetext{
${ }^{24}$ The model has been applied in different data structures, such as time series (Campa and Goldberg, 2005) and panel data sets for both aggregate country- or industry-level studies and detailed producer- or product-level studies (Goldberg and Campa, 2010, Nakamura and Zerom, 2010).

${ }^{2 \tau}$ We also evaluated opportunity cost pass through for oil spot market prices to oil fired power plants. The passthrough patterns of natural gas and oil are very similar, and oil accounts for only a small share of electricity generation, so we present only pass-through coefficients for coal and natural gas. More detailed results for oil are available upon request.
} 


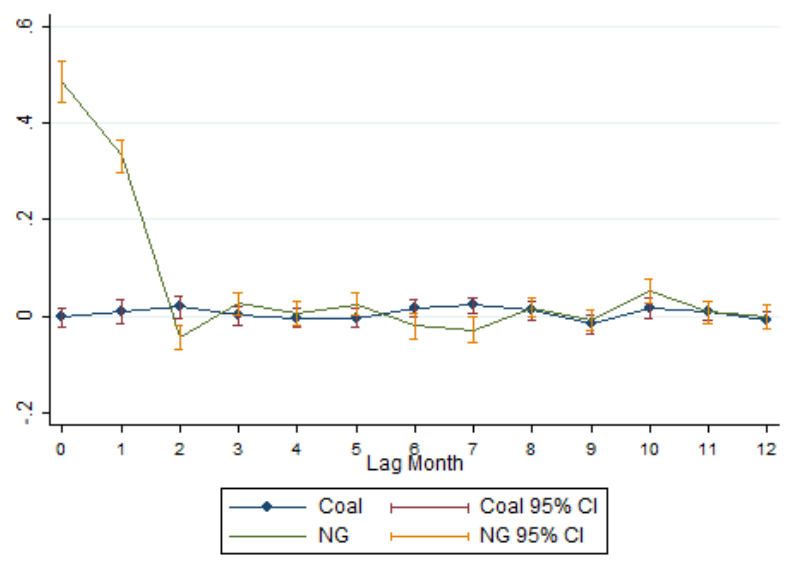

Figure 3: Pass-through Coefficients for Coal and Natural Gas

Note: Lines indicate the point estimates for coefficients associated with each month's lagged fossil fuel spot market price. Whiskers represent $95 \%$ confidence intervals.

also check the empirical model in equation (2) with 24 lags for coal. However, the long-run the pass-through after 24 months only increases to 0.22 (with a standard error of 0.03 ) ${ }^{26}$

The findings in this section are in one way unsurprising and another way surprising. They are unsurprising in that natural gas spot prices pass through to electricity generators more quickly than coal prices: coal is procured via longer terms contracts than natural gas. The result also provides evidence in support of the existing literature. Fabra and Reguant (2014) find that fossil fuel price pass through estimates to wholesale electricity prices are noisily estimated relative to pollution permit prices. The authors argue that fuel market spot prices may be an imperfect proxy for power plants true costs. Our result suggests that is likely the case, at least for coal fired power plants.

The magnitudes of how quickly spot prices manifest in procurement costs is somewhat surprising ${ }^{27}$ The opportunity cost pass-through for natural gas is almost complete within two months. Conversely, the opportunity cost pass-through for coal, even over a year, is still very small. It suggests that as more electricity is produced using natural gas the electricity prices could become more sensitive to short run changes in fuel price. However, a more complete structural model accounting for strategic considerations of electricity producers is needed in order to determine how procured fuel prices are passed on to wholesale electricity prices.

It is important to note that the estimated opportunity cost pass through coefficients are identified off

\footnotetext{
${ }^{26}$ These results are robust to using SNL Energy's reported spot prices, rather than Bloomberg data, for the basins where SNL Energy provides spot market data.

${ }^{27}$ In the appendix, we show that these results for coal opportunity cost pass through are consistent across each of the three coal basins. We take this as evidence that the opportunity cost pass through estimates are not hiding the effects of unobservable coal characteristics.
} 
monthly variation in commodity prices. In that sense, the estimates here clearly reflect opportunity cost pass through rather than traditional pass through. The distinction is important when the results are interpreted. Long-run changes in commodity prices driven by banning types of coal production or a production tax on coal would not be consistent with our analysis and would likely eventually pass through, at least partially, to coal fired power plants and therefore wholesale electricity prices.

\subsection{Contract Duration}

One possible explanation for the different patterns between coal and natural gas procurement costs noted above may be differences in the way those fuels are purchased. Joskow (1987) finds that coal is typically purchased on longer term contracts as the level of relationship-specific investments for the coal fired power plant increases. The homogeneity of natural gas reduces the need for relationship-specific investments and thus long-term contracting. In this section we take advantage of EIA's (limited) information on contract duration to explore how opportunity cost pass through varies with contract duration. Unfortunately, EIA does not have precise information on contract duration for each delivery. EIA labels a transaction as either "spot" or "contract". The EIA definition of a "spot" transaction is somewhat atypical. In our data, it means "fuel received under a purchase order or contract with a duration of less than a year". Otherwise, a transaction is defined as "contract". This implies that both true spot transactions as well as contracts up to a year are included in the "spot" category. We return to this measurement issue when discussing our results. For "contract" purchases, EIA also reports the month and the year when a purchase order expires, but reporting this information is optional.

To illustrate the data, we begin by demonstrating the variation in delivered contract prices within a delivery month and coal basin for spot contracts only. We also graph the appropriate coal commodity spot price on each panel to document where the spot price sits relative to the delivered prices generators were receiving that month. The results are presented in Figure 4. The results demonstrate the significant heterogeneity of delivered coal prices. This variance could be driven by within basin differences in transportation costs or coal characteristics. The dispersion displayed here is not explained by lagged spot prices suggesting that EIA's idiosyncratic definition of spot prices is not the primary driver of the variance in spot prices, although of course it may play a role. The delivered price includes transportation costs here which may drive some of the variation. Similar graphs subtracting out the estimated transportation costs using the process described above (available upon request) tell a similar story. While transport costs likely play a large role in shifting the PRB distribution to the right, the coefficient of variation is roughly the same across the three basins.

We estimate equation (2) on subsets of the data to evaluate opportunity cost pass through by contract 


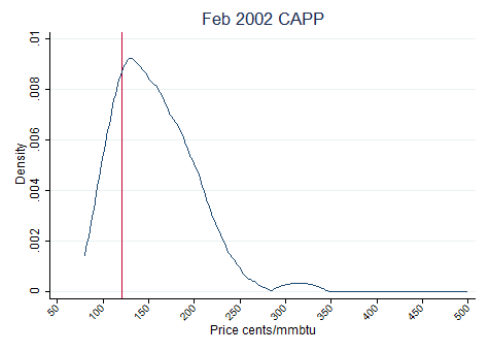

(a) Feb. 2002, CAPP

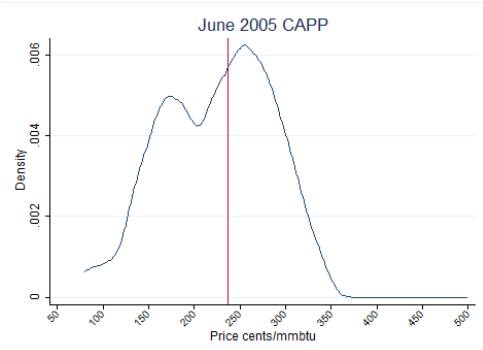

(d) June 2005, CAPP

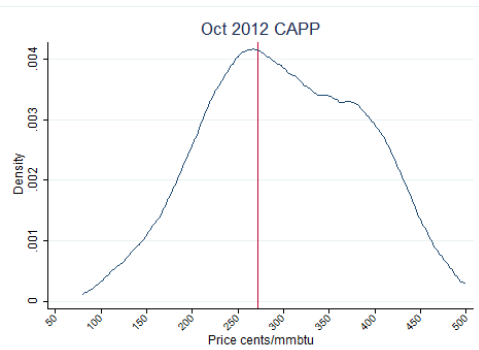

(g) Oct 2012, CAPP

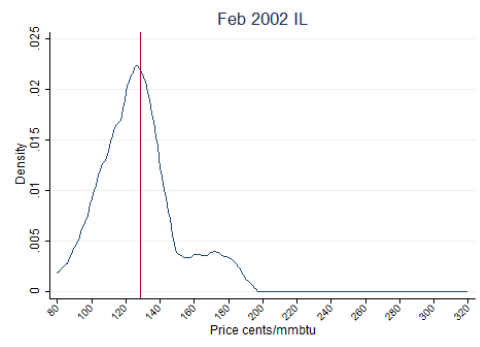

(b) Feb. 2002, IL

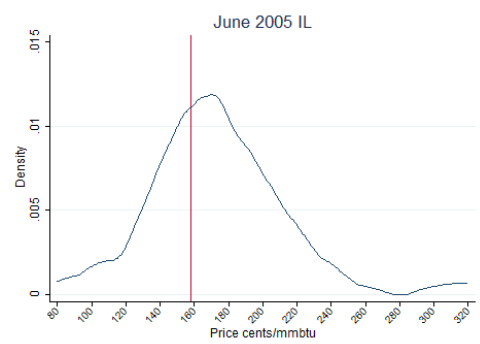

(e) June 2005, IL

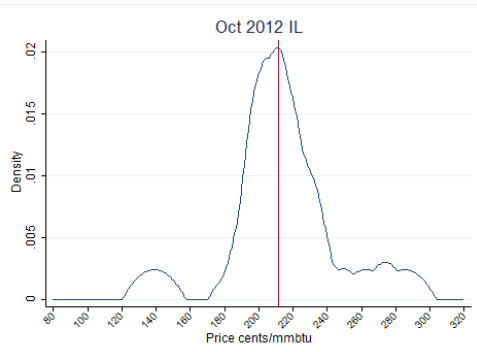

(h) Oct 2012, IL

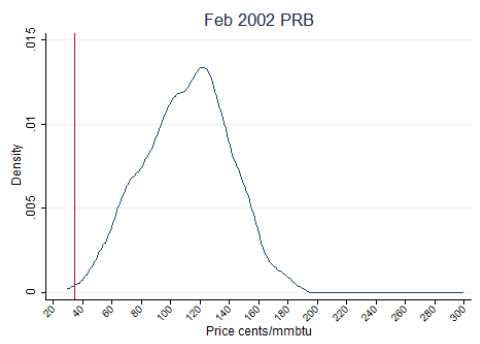

(c) Feb. 2002, PRB

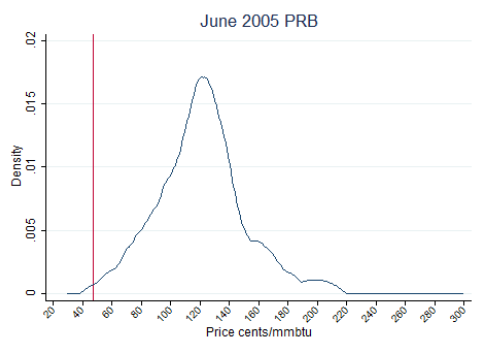

(f) June 2005, PRB

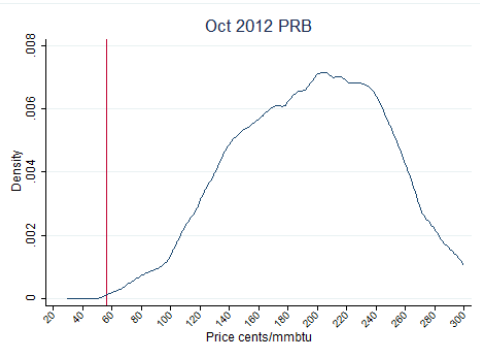

(i) Oct 2012, PRB

Figure 4: Distribution of Delivered Coal Prices by Delivery Month and Coal Basin

Note: each panel reports the distribution of observed delivered coal prices for spot contracts, as defined by EIA, for a single, arbitrarily chosen, month in each major coal basin. The vertical line indicates the level of spot prices for that month and basin. The delivered price includes transportation costs and transportation costs are much higher in PRB than the other basins. 
duration. We estimate our baseline equation on spot, intermediate and long contracts for coal and natural gas separately for a total of six regressions. Intermediate and long contracts are categorized by the cutoff of the sample median of contract length, which is approximated by the time period between the current month and the expiration month. In table 2 we report the estimated opportunity cost pass through coefficients for each of those sub-samples for twelve months of lagged spot price indices. Columns 1-3 report the results for coal deliveries. For coal delivered on spot contracts, we find limited evidence of positive opportunity cost pass through. While the contemporaneous months opportunity cost pass through coefficient is negative, and statistically insignificant, lag months 1-4 are positive, and again not significant. We cannot reject the hypothesis that the opportunity cost pass through on spot contracts is positive and significant for months $0-2($ coefficient $=0.13, \mathrm{t}$-stat $=2.70)$ and $0-6$ months $($ coefficient $=.13 \mathrm{t}$-stat $=2.30)$. In contrast, there is no evidence of opportunity cost pass through for intermediate and long contracts on coal. There is no evidence of positive opportunity cost pass through for those time horizons for intermediate contracts, and smaller, but statistically significant opportunity cost pass through within 0-2 months for long term contracts driven by the positive contemporaneous point estimate ${ }^{28}$

Next, we consider columns 4-6, which report natural gas opportunity cost pass through coefficients for different contract durations. Opportunity cost pass through is higher for all contract types for natural gas as compared to coal. That said, there is significantly higher opportunity cost pass through for shorter natural gas duration contracts. Both spot and intermediate contemporaneous opportunity cost pass through is positive with a slightly higher point estimate for spot transactions, although the difference is not statistically significant. The opportunity cost pass through rates on spot contracts are significantly higher for months 0-3 summed than on intermediate length contracts.

The results of our analysis in this section provide some suggestive evidence that contract duration is correlated with how quickly commodity spot prices manifest in power plant procurement costs. Opportunity cost pass through on both coal and natural gas are higher in the spot market than the contract markets. The differences in opportunity cost pass through across fuels are much larger than the differences across contract types within fuels. The estimation of opportunity cost pass through by contract type is difficult for at least two reasons, first there are a relatively small number of deliveries in the non-modal contract type for each fuel, leading to imprecise estimates. Second, and more importantly, the definition of spot contracts is somewhat atypical. To the extent that we are lumping true "spot" transactions with longer term contacts, we may be understating the level of opportunity cost pass through for spot transactions.

\footnotetext{
${ }^{28}$ We also compared the descriptive statistics for coal delivered under each contract type. We do not find systematic differences in the characteristics of coal across contract types.
} 
Table 2: Regression Results by Contract Duration: Coal and Natural Gas

\begin{tabular}{|c|c|c|c|c|c|c|}
\hline & (1) & Coal & $(3)$ & (4) & $\begin{array}{c}(5) \\
\text { Natural Gas }\end{array}$ & (6) \\
\hline & Spot & Intermediate & Long & Spot & Intermediate & Long \\
\hline$P_{0}$ & -0.03 & 0.03 & $0.06^{* *}$ & $0.47^{* * *}$ & $0.40^{* * *}$ & 0.23 \\
\hline$P_{1}$ & 0.06 & -0.01 & -0.02 & $0.29^{* * *}$ & $0.34^{* *}$ & $0.34^{* * *}$ \\
\hline$P_{2}$ & 0.10 & 0.00 & 0.03 & -0.01 & -0.04 & 0.00 \\
\hline$P_{3}$ & 0.03 & -0.02 & 0.01 & -0.00 & -0.04 & 0.00 \\
\hline$P_{4}$ & 0.02 & 0.02 & -0.01 & -0.01 & -0.09 & 0.02 \\
\hline$P_{5}$ & $-0.12^{*}$ & -0.02 & -0.01 & 0.03 & -0.04 & 0.06 \\
\hline$P_{6}$ & $0.07^{*}$ & $0.06^{* *}$ & 0.03 & -0.02 & 0.08 & 0.02 \\
\hline$P_{7}$ & 0.00 & -0.05 & -0.02 & $-0.06^{* *}$ & 0.03 & $-0.15^{* *}$ \\
\hline$P_{8}$ & -0.04 & 0.02 & 0.03 & 0.02 & -0.07 & -0.02 \\
\hline$P_{9}$ & -0.04 & 0.05 & -0.02 & 0.01 & -0.15 & -0.02 \\
\hline$P_{10}$ & 0.02 & -0.02 & 0.01 & 0.03 & -0.04 & 0.06 \\
\hline$P_{11}$ & $0.17^{* *}$ & 0.03 & 0.00 & 0.00 & -0.03 & 0.02 \\
\hline$P_{12}$ & -0.05 & 0.00 & $0.05^{*}$ & -0.04 & 0.06 & -0.06 \\
\hline Observations & 673 & 1511 & 2290 & 15731 & 898 & 1628 \\
\hline Adjusted $R^{2}$ & 0.024 & 0.043 & 0.027 & 0.022 & 0.038 & 0.014 \\
\hline
\end{tabular}

Note: The table shows estimated opportunity cost pass through coefficients by month, contract duration and fuel type. Each column reports the results of a separate regression on a fuel-contract duration specific subset of the data. ${ }^{*} p<0.1,{ }^{* *} p<0.05,{ }^{* * *} p<0.01$.

\subsection{Variations by Regulatory Status}

One attractive feature of our data is that we observe regulation status of each power plant in our sample. We investigate the how quickly commodity spot prices manifest in procurement costs in regulated power plants versus divested or deregulated plants in this subsection. There is evidence that deregulation affects firms' fuel procurement practices (Chan et al., 2013, Cicala, 2015, Jha, 2015). We are not aware of any study which attempts to determine if the speed with which spot prices manifest in procurement costs varies with regulatory status.

\subsubsection{Post-deregulation Comparison}

We estimate the following variant of equation (2) to determine differences in opportunity cost pass through by regulatory status:

$$
\begin{aligned}
\Delta \log \left(\text { Fuel Price }_{i t}^{f}\right)= & \alpha+\sum_{k=1}^{12} \gamma_{k}^{f} \cdot \Delta \log \left(\text { Spot Price }_{t-k}^{f}\right) \cdot 1\left[\text { Deregulation }_{i}\right] \cdot 1\left[\text { Fuel }_{f}\right] \\
& +\sum_{k=1}^{12} \beta_{k}^{f} \cdot \Delta \log \left(\text { Spot }_{\text {Price }}^{f}{ }_{t-k}\right) \cdot 1\left[\text { Fuel }_{f}\right]+\Psi \cdot X+\epsilon_{i t}^{f}
\end{aligned}
$$




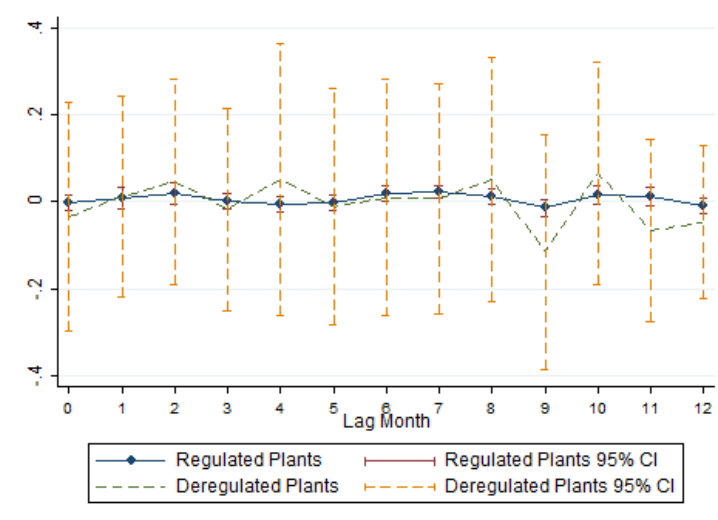

(a) Coal Transactions

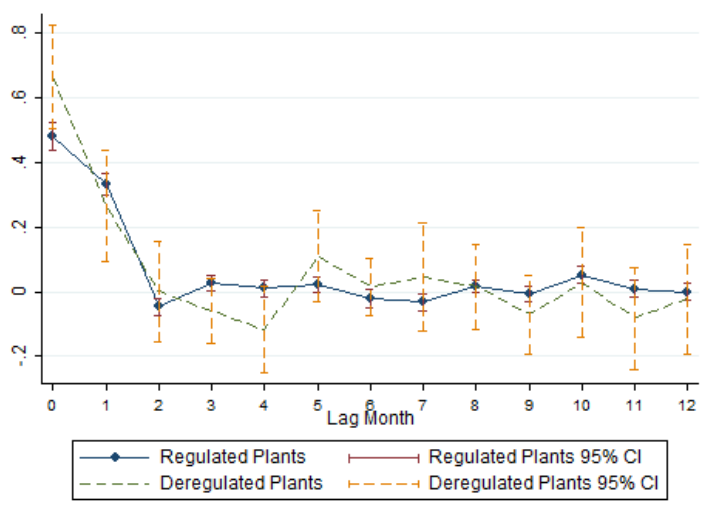

(b) NG Transactions

Figure 5: Pass-through Elasticity: Regulated vs. Deregulated

Note: deregulated plants are defined as divested ones of the independent power producers.

where $1[$ Deregulation $]$ is an indicator variable taking a value of 1 if a plant is a divested independent power producer. $\beta^{f}$ now measures the pass-through elasticity of the regulated plants for fossil fuel $f, \gamma_{f}$ measures the deviation of pass-through elasticity of the deregulated plants relative to the regulated counterparts for fuel $f$. As before, the coefficients are identified off variation in changes of input spot prices within a fuel type, month of year, and a deregulated (or regulated) power plant owning firm.

Figure 5 plots the estimated coefficients along with $95 \%$ confidence intervals for coal and natural gas purchases by regulatory status. The Figure shows that while coal opportunity cost pass through does not vary with regulatory status, natural gas opportunity cost pass through is significantly more rapid in deregulated plants. This is indicated by the significant difference in the estimates for the contemporaneous month. In the Appendix we also show coefficient estimates numerically to emphasize these statistically significant differences. Specifically, natural gas has higher opportunity cost pass through after one month (.67 versus $.48)$ and two months (.93 versus .81) in deregulated versus regulated power plants. This indicates that given a $1 \%$ increase in the natural gas spot prices, on average the increase of natural gas procurement prices in deregulated plants is larger by $0.19 \%$ than that in regulated plants within one month.

For coal, on the other hand, there are no distinguishable pattern of pass-through between regulated and deregulated power plants. The estimated opportunity cost pass through rates are small for all of the months for both regulated and deregulated plants, even though the estimates are noisier for deregulated plants. The appendix also provides evidence that these results hold across each of the coal basins independently. 


\subsubsection{Difference-in-difference Approach}

We further analyze differential opportunity cost pass through patterns by regulatory status via a differencein-difference approach. Previous literature documenting evidence that deregulation affects firms' fuel procurement practices all exploit a difference in difference design (Chan et al., 2013, Cicala, 2015, Jha, 2015). Taking advantage of pre-deregulation periods as a counterfactual, we reevaluate our previous findings based on simple post-deregulation differences and provide more informative interpretation regarding the comparison between regulated versus deregulated power plants. Regulatory status is non-random and the data are not ideal for this exercise. For that reason we do not claim to have estimated a causal effect. We do believe these results provide suggestive evidence that opportunity cost pass through is faster and more complete in deregulated markets.

Before 1998, many U.S. power plants faced output price regulation. Beginning in 1998, some U.S. states introduced auction-based market mechanisms for electricity supply, while other states remained under output price regulation. We collect monthly shipment-level data on fuel purchase information for the U.S. power plants during 1995-1998 from EIA's FERC 423 form. The reason why the pre-deregulation sample only dates back to Jan 1995 is because it is the earliest month for our fossil fuel commodity spot price data. Taking advantage of the "pre-1998" sample, we are able to alleviate some confounding factors in associated differential opportunity cost pass through and regulatory status. For instance, deregulated natural gas power plants tend to be located in Northeast, Texas or California, where natural gas generation accounts for a larger share in the generation mix and power plants are located nearer to trading hubs ${ }^{29}$

One critical caveat of the FERC 423 form data is that once divested, plants were no longer required to report fuel purchase information to FERC, and EIA did not resume collection of fuel purchase information from deregulated power plants until 2002. Thus, deregulated plants which were sold before 2002 have a gap in reporting. This is the reason why we exploit disjoint periods of 1995-1998 and 2002-2012 as samples for pre- and post-deregulation.

Other inconsistencies exist between the pre- and post-deregulation samples. The pre-1998 data does not provide specific dates of expiration for "contract" purchases (orders expiring after more than 12 months) unlike the post-2002 data. This limits our ability to further categorize "contract" purchases based on contract length 30 Therefore, combining the two data sets, we can only separate transactions into "spot" (i.e., expiring within 12 months) and "contract" transactions.

\footnotetext{
${ }^{29}$ We thank for the anonymous referee for raising these arguments.

${ }^{30}$ The pre-1998 sample of FERC 423 data provides information on whether the number of months remaining on a contract is over 24 months. We tried to use this as criterion to separate "contract" purchases to achieve data consistency before and after deregulation. However, there are too few observations for contracts over 24 months to separately estimated their opportunity cost pass through in this specification.
} 
We apply the following difference-in-difference empirical specification form:

$$
\begin{aligned}
\Delta \log (\text { Fuel Price })_{i t}^{f}= & \alpha+\sum_{k=0}^{12} \delta_{k}^{f} \cdot \Delta \log (\text { Spot Price })_{t-k}^{f} \cdot 1[\text { Deregulated }]_{i} \\
& +\sum_{k=0}^{12} \gamma_{k}^{f} \cdot \log (\text { Spot Price })_{t-k}^{f} \cdot 1[\text { Year }>1998]_{t} \\
& +\sum_{k=0}^{12} \beta_{k}^{f} \cdot \Delta \log (\text { Spot Price })_{t-k}^{f} \cdot 1[\text { Year }>1998]_{t} \cdot 1[\text { Deregulated }]_{i}+\Psi \cdot X+\epsilon_{i t}^{f},
\end{aligned}
$$

The empirical model is applied separately to coal and natural gas, with $f$ indicating the fuel type. For coal purchases, the cross-section unit $i$ is a transaction from an extraction type of coal mine (surface/underground mining) from a delivery county to a power plant; for natural gas, $i$ is a power plant. Due to limited data on Illinois Basin coal usage before deregulation and environmental regulation implemented at the same time, for coal purchases, we focus on central Appalachian coal and the Powder River Basin coal during 1997-1998 as pre-deregulation counterfactuals. For natural gas purchases, we take advantage of pre-deregulation sample between 1995-1998. 1[Year $>1998]_{t}$ is an indicator taking value of 1 after 1998 (2002-2012), and 0 otherwise. $1[$ Deregulated $]$ is an indicator variable taking value of 1 if a plant was eventually divested as an Independent Power Producer. $X$ is a set of control variables including plant fixed effects and month-of-year fixed effects; for coal purchases, it also incorporates coal characteristics (ash content, heat content, sulfur content), dummy variable of whether the coal is from an outside state, indicator of coal mine type, and monthly changes of rail cost adjusted factor which control for changes of rail delivery cost adjusted for productivity shocks. Within each fuel type, we also apply the above empirical model separately for purchases under different contract duration: (1) "spot" and (2) "contracts" purchases.

For natural gas transactions, the estimated difference-in-difference coefficients associated with each lagged month (e.g., $P_{1}$ indicates the coefficient for the first lagged month, etc.) are shown in Table 3 , with column (1) - (3) containing results for all sample observations, "spot" purchase observations and "contract" purchase observations. When all the sample observations are included coefficients indicate that natural gas spot prices pass on much more quickly to procurements costs for deregulated plants relative to their regulated counterparts since the coefficient on " $P_{0}$ " is positive and statistically significant. This is consistent with the empirical findings based on simple post-deregulation comparison.

When we estimate separate coefficients for contract durations of different lengths, the coefficient estimate for contemporaneous month stays positive. The "contract" opportunity cost pass through is comparable to the full sample, while the spot purchases are somewhat lower, although the difference is not statistically 
Table 3: Deregulated Status and NG Pass-through Patterns: Diff-in-diff Analysis

\begin{tabular}{lccc}
\hline \hline & Full Sample & "Spot" Purchases & "Contract" Purchases \\
\hline$P_{0}$ & $0.428^{* *}$ & 0.242 & $0.409^{*}$ \\
$P_{1}$ & -0.0762 & 0.103 & -0.115 \\
$P_{2}$ & -0.114 & $-0.257^{*}$ & -0.0526 \\
$P_{3}$ & 0.0487 & -0.106 & 0.137 \\
$P_{4}$ & -0.0718 & 0.00770 & -0.158 \\
$P_{5}$ & 0.0141 & $0.204^{* *}$ & -0.0382 \\
$P_{6}$ & -0.0314 & $-0.213^{*}$ & 0.0749 \\
$P_{7}$ & 0.0754 & 0.0118 & 0.146 \\
$P_{8}$ & 0.0314 & 0.128 & -0.0374 \\
$P_{9}$ & -0.111 & $-0.234^{* *}$ & -0.104 \\
$P_{10}$ & 0.0168 & 0.0861 & 0.0297 \\
$P_{11}$ & -0.100 & -0.111 & $-0.225^{*}$ \\
$P_{12}$ & -0.0694 & -0.0422 & -0.00718 \\
\hline Observations & 35448 & 17404 & 18044 \\
Adjusted $R^{2}$ & 0.050 & 0.024 & 0.092 \\
\hline \hline
\end{tabular}

Note: Coefficients represent the difference in opportunity cost pass through in deregulated plants relative to the pre-deregulation time period (e.g., the $\beta$ coefficients in equation 4 above). Note the pre- and post-regulation data come from different E.I.A. forms with slightly different reporting requirements. See main text for details. ${ }^{*} p<0.1,{ }^{* *} p<0.05,{ }^{* * *} p<0.01$.

significant. For several lagged terms in the contract specific results, the difference-in-difference coefficients are significantly negative. For specifications (2) and (3), we use the delta method to estimate cumulative procurement cost pass-through rates for "spot" and "contract" observations. For both "spot" and "contract purchases, cumulative differences in pass-through rates are statistically insignificant with the exception of the 2-month cumulative pass-through. For "spot purchases, the 2-month cumulative pass-through is $34 \%$ larger for plants in deregulated markets and significant at the $5 \%$ level. For "contract" purchases, the 2-month cumulative pass-through for deregulated plants is larger at the $10 \%$ significant level with a magnitude of approximately $29 \%$. From this perspective, the results of faster pass-through for deregulated power plants still hold when we look into contract durations of different lengths.

We also estimate a similar specification for coal opportunity cost pass through. The results are similar, opportunity cost pass through is faster and more complete in deregulated markets post-deregulation than in non-deregulated markets controlling for pre-deregulation differences. The results here somewhat more difficult to interpret because our baseline specification estimated very little opportunity cost pass through. We cautiously interpret this as suggestive evidence of a trend towards faster and more complete opportunity cost pass through in coal plants in deregulated jurisdictions.

Our research design does not let us identify the cause of this difference. However, this is consistent with deregulated plants choosing contract durations in a strategically different way compared to regulated plants. We view this as consistent with the broader literature on this topic which finds that deregulation 
impacts procurement mechanisms (Chan et al. 2013; Cicala, 2015, Jha, 2015). However, given that strategic incentives are possibly different in deregulated and regulated plants and our research design does address mechanisms, we prefer to focus on the net effects of the pooled results and leave the optimal composition of long versus short term natural gas contracts due to deregulation to future work.

It is reasonable that the rate which commodity prices manifest in procurement costs for natural gas differ by the downstream regulatory status. In the context of Weyl and Fabinger (2013), pass through to retail prices is a function of downstream competition parameters. It is possible the same is true for input contract type. Regulatory status in the electricity wholesale market influences those competition parameters. However, because we do not have random assignment of regulatory status we do not attribute this difference as the causal impact of regulation. For example, the characteristics of the downstream electricity market which lead regions to deregulate are likely to be correlated with some measure of that region's competition parameters. Generalizing these results out of sample is therefore not valid. Even if opportunity cost pass through rates vary by market type, the implications for electricity generators are not clear. Knittel et al. (2015b) finds that gas-fired units in regulated markets are more sensitive to changes in gas price, a result the authors attribute to the available capacity across market types. For all these reasons, we urge caution in interpreting the mechanism behind this finding.

\subsection{Price Increases versus Decreases}

The stark difference between procurement costs between coal and natural gas with respect to commodity prices is possibly explained by different hedging strategies. For example, the on-site storage costs of coal versus natural gas are likely to be different. The average coal generator keeps around 60 days worth of fuel in inventory on site (EIA (2014)) while most natural gas units have little or no on-site storage. As a result, there could be differences in how coal versus natural gas generators hedge against input price increases versus decreases. We therefore estimate the model allowing for opportunity cost pass through to vary by fuel price increases versus decreases 31

$$
\begin{aligned}
\Delta \log \left(\text { Fuel Price }_{i t}^{f}\right)= & \alpha+\sum_{k=1}^{12} \delta_{k}^{f} \cdot \Delta \log \left(\text { Spot Price }_{t-k}^{f}\right) \cdot 1\left[\text { Negative }_{t-k}^{f}\right] \cdot 1\left[\text { Fuel }_{f}\right] \\
& +\sum_{k=1}^{12} \beta_{k}^{f} \cdot \Delta \log \left(\text { Spot Price }_{t-k}^{f}\right) \cdot 1\left[\text { Fuel }_{f}\right]+\Psi \cdot X+\epsilon_{i t}^{f}
\end{aligned}
$$

\footnotetext{
${ }^{31}$ Kilian and Vigfusson (2009) shows that estimating these equations replacing decreases in price with zeros lead to censored regressions that are biased towards finding asymmetric pass-through. The authors suggest a similar estimation strategy to the one we employ here.
} 
where $1[$ Negative] is an indicator variable taking the value of one if the commodity spot price of fuel $f$ decreased $k$ months ago. $\beta^{f}$ now measures the pass-through coefficient given a market price increase for fossil fuel $f$. $\delta_{f}$ instead measures the difference of the pass-through coefficient given a market price decrease relative to an increase for fuel $f{ }^{32}$ The coefficients are identified off variation in increases (or decreases) of input spot prices within a fuel type, month of year, and a power plant owning firm.

Figure 6 plots the mean pass-through coefficients for positive versus negative commodity market price changes along with $95 \%$ confidence intervals for coal and natural gas. For coal, there is no obvious asymmetric pass-through pattern in response to positive or negative coal spot market shocks. The responses to coal spot price increases and decreases at different lags are not statistically different from each other except for the month 11 lags which we attribute to noise.

For natural gas purchases, power producers' procurement prices respond quickly (within 1 month) to both negative and positive natural gas spot market shocks. Yet, a 1-month lag negative shock passes on to the procurement costs more than a 1-month lag positive price changes (by $0.19 \%$ given a $1 \%$ change in natural gas spot price in absolute value). Positive shocks are significantly more likely to be passed through after three months, possibly after natural gas market hedging options have been exploited. Both results are consistent with natural gas plants being somewhat strategic in their procurement behavior. If a plant were to hold natural gas reserves on site and the spot price of natural gas increases, the plant could use its reserves for production in order to be more competitive in wholesale market auctions. Conversely when spot natural gas prices decrease the incentive to draw down reserves would be reduced. Such behavior would produce the estimated results for asymmetric pass through of natural gas price increases and decreases. However, we have no data on inventories at the plant level nor inventories over time. As a result, the above explanation purely speculative.

Focusing on the net effect of the first two months when majority of the pass-through responses occur, a Wald test rejects (at 5\% significance level) the null hypothesis that the sum of the pass-through responses under a positive shock is statistically indifferent from the sum under a negative shock. Negative shocks pass on to procurement costs faster (by $0.11 \%$ given a $1 \%$ change in natural gas spot prices) than positive shocks within the first two months.

In sum, we find that coal continues to exhibit no strong difference in opportunity cost pass through for increases versus decreases. The lack of asymmetric pass-through for coal prices is consistent with the general result that coal spot prices are not a good proxy for the delivered cost of coal. For natural gas we do find some weak evidence of opportunity cost pass through asymmetries by the direction of natural gas spot market price changes. While this is possibly consistent with strategic behavior on the part of natural

\footnotetext{
${ }^{32}$ Table A3 in the Appendix shows $\beta_{k}^{f}$ and $\delta_{k}^{f}$ for up to 6 months.
} 


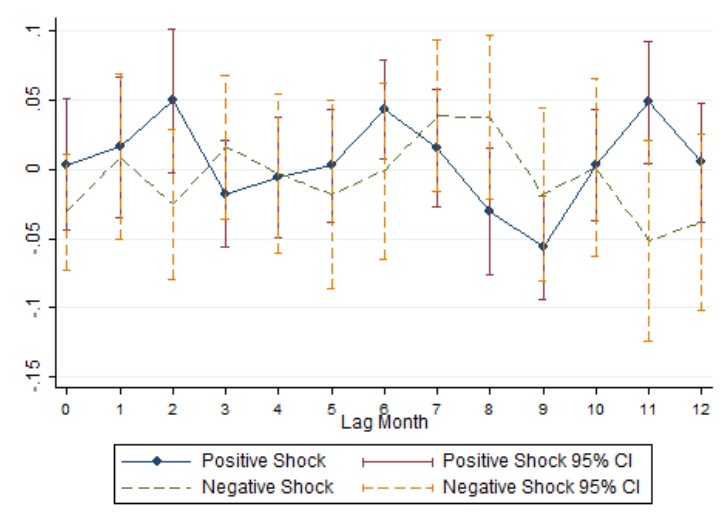

(a) Coal Transactions

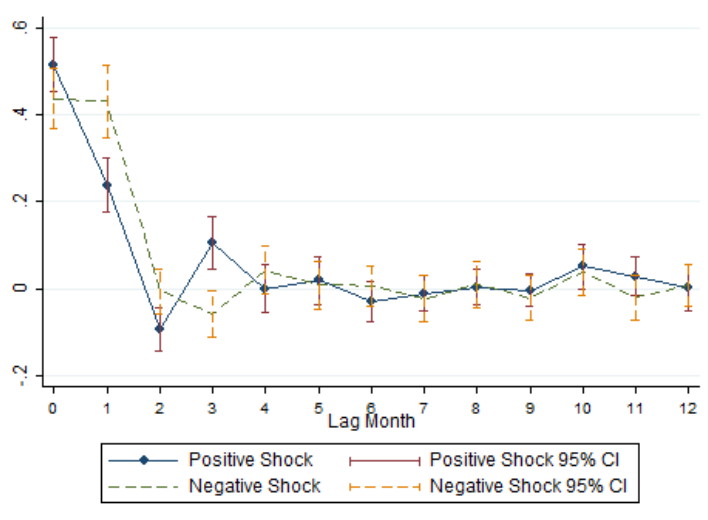

(b) NG Transactions

Figure 6: Pass-through Elasticity: Positive vs. Negative Shocks

Note: a positive shock means an increase in the relevant fossil fuel spot market price.

gas firms we again urge caution in carrying these findings out of sample.

\section{Conclusion}

In this study, we investigate how commodity spot price changes are reflected in procurement costs of coal and natural gas fired electricity generators. We find that coal spot price pass through to procurement costs is very slow and very incomplete. There also appears to be no difference in opportunity cost pass through of coal spot market price changes even when grouping coal by type. As a result, we take this as strong evidence that coal opportunity cost pass through is slow, incomplete and does not vary by the source of coal.

Conversely, natural gas commodity price changes are rapidly and nearly completely reflected in procurement costs within the two months immediately following a perturbation. The finding is even stronger deregulated plants relative to regulated plants. We also find evidence that spot price decreases are more quickly reflected than increases.

Our findings have implications for both the electricity and business sectors as an increasingly large share of electricity production occurs from natural gas. Volatility in natural gas market prices is quickly transmitted to procurement costs of power producers which has at least two effects. First, it potentially increases market efficiency by ensuring that electric power plants pay the actual opportunity cost of the fuel inputs they employ. Secondly, if volatile fuel procurement costs are subsequently passed through to electricity wholesale prices, it could reduce the welfare of risk averse electricity consumers. As a result, further study is needed to identify whether and how input procurement costs manifest in wholesale prices in the electricity markets and if so how the risk consumers face compares to the gains from more dispatch that 
better reflect opportunity cost of fuel. We note that because our identification is driven off month-to-month variation in fossil fuel prices our estimates do not speak to the effects of long-run changes like mine-mouth carbon pricing.

The results of our study also inform future studies in the electric power industry. The adjustment lag between fossil fuel spot prices and procurement receipt prices for power plants implies that spot prices do not always reflect the true opportunity costs of using the fuel. It has implications on how to apply the static model of measuring market power commonly used in the electricity market: when researchers construct regional supply curves, it might be appropriate to use relevant fossil fuel spot market prices to calculate the marginal costs of natural-gas-fired generators. For the marginal cost calculation of coal-fired generators, we should instead use observed coal receipt data from the E.I.A or other sources.

In the appendix we demonstrate that the adjustment lag between fossil fuel spot prices and procurement receipt prices for power plants also has methodological value. We construct counterfactual electricity market marginal cost curves (known as dispatch curves) for two widely-studied markets, California (CAISO) and Pennsylvania, Jersey and Maryland (PJM). We create two marginal cost curves for each market each month of each year of our sample: one based on spot fuel prices and the other based on receipt fuel prices. Our finding suggests that for coal fired power plants coal spot prices are not a good measure of fuel procurement costs when measured at the month level. The results are consistent with Fabra and Reguant (2014) which finds that pass through for fuel prices is significantly noisier than those for emissions permits. This finding has implications on constructing counterfactual competitive supply curves commonly used in the static approach of measuring market power in the electricity market ${ }^{33}$ Much of the literature use respective fossil fuel spot prices to calculate the marginal costs of generating units and build counterfactual competitive supply curves. Our results imply that while this might be appropriate for natural-gas-fired units, it might not be for coal-fired units.

We also document evidence that natural fossil fuel spot prices changes are passed through to procurement costs more quickly in deregulated markets. However, our findings are not causal since we observe no variation in regulatory status within a plant across time in our sample period. Our results are consistent with existing literature which finds that deregulated electric utility firms bargain to pay lower costs for fuel prices in that we find differences in pass-through between regulated and deregulated natural gas power plants Chan et al. 2013). We are not aware of any study which documented a discrepancy for natural gas power plants.

The opportunity cost pass through estimates provide suggestive evidence that the benefits of the major fall in natural gas prices have not been captured by natural gas extraction firms. The variation we exploit

\footnotetext{
${ }^{33}$ See Borenstein and Bushnell (1999) and Borenstein et al. (2002) for the electricity market in California, Wolfram (1999) for the electricity market in UK, and Mansur (2007) for the Pennsylvania, New-Jersey, Maryland (PJM) electricity market.
} 
in this study is not from the fracking-induced price collapse in natural gas, but the near instantaneous opportunity cost pass through in natural gas spot prices to natural gas consumers suggest that inexpensive natural gas is passed through to electricity generators.

Our results also suggest possible opportunities of future work. One limitation of our study that we do not identify the contribution of different possible channels underlying the differences in pass-through by regulatory status nor price increases versus decreases for natural gas nor the differences between coal and natural gas. For instance, an inventory model might be a useful way to gain insights into empirical results for coal and natural gas pass through. A similar model may help explain asymmetries in pass through for price increases and decreases for natural gas. We leave such structural modeling to future work.

\section{References}

Adachi, Takanori and Takeshi Ebina, "Cost pass-through and inverse demand curvature in vertical relationships with upstream and downstream competition," Economics Letters, 2014, 124 (3), 465-468.

Aguirre, Iñaki, Simon Cowan, and John Vickers, "Monopoly Price Discrimination and Demand Curvature," American Economic Review, September 2010, 100 (4), 1601-1615.

Borenstein, Severin, A Colin Cameron, and Richard Gilbert, "Do Gasoline Prices Respond Asymmetrically to Crude Oil Price Changes?," The Quarterly Journal of Economics, February 1997, 112 (1), $305-39$.

_ and James B. Bushnell, "An Empirical Analysis of the Potential for Market Power in California's Electricity Industry," Journal of Industrial Economics, 1999, 47 (3), 285-323.

_, _, and Frank A. Wolak, "Measuring Market Inefficiencies in California's Restructured Wholesale Electricity Market," American Economic Review, December 2002, 92 (5), 1376-1405.

Busse, Meghan R and Nathaniel O Keohane, "Market Effects of Environmental Regulation: Coal, Railroads, and the 1990 Clean Air Act," The RAND Journal of Economics, 2007, 38 (4), 1159-1179.

Campa, José Manuel and Linda S Goldberg, "Exchange Rate pass-through into Import Prices," Review of Economics and Statistics, 2005, 87 (4), 679-690.

Chan, H. Ron, Harrison Fell, Ian A. Lange, and Shanjun Li, "Efficiency and Environmental Impacts of Electricity Restructuring on Coal-Fired Power Plants," Technical Report 4160, CESifo Group Munich 2013. 
Cicala, Steve, "When Does Regulation Distort Costs? Lessons from Fuel Procurement in U.S. Electricity Generation," American Economic Review, January 2015, 105 (1), 411-444.

EIA, "Cost and Quality of Fuels for Electric Plants Report," Technical Report, U.S. Energy Information Administration 2010. accessible at: http://www.eia.gov/electricity/cost quality/.

_ , "Annual Electric Generator Report Form EIA 923 Data," Technical Report, U.S. Energy Information Administration 2012. accessible at: www.eia.gov/electricity/data/eia923/.

_ , "Central Appalachian (CAPP) coal spot prices affect markets for coal and electric power," Technical Report, U.S. Energy Information Administration September 2012.

_ , "Electricity Monthly Update, March edition," Technical Report, U.S. Energy Information Administration 2014. accessible at: www.eia.gov/electricity/monthly/update/archive/march2014.

Fabra, Natalia and Mar Reguant, "Pass-Through of Emissions Costs in Electricity Markets," American Economic Review, September 2014, 104 (9), 2872-2899.

Fell, Harrison, "EU-ETS and Nordic Electricity: A CVAR Analysis," The Energy Journal, 2010, 0 (2), $1-26$.

_, Beat Hintermann, and Herman R. J. Vollebergh, "Carbon Content of Electricity Futures in Phase II of the EU ETS," Technical Report 43672013.

_, Shanjun Li, and Anthony Paul, "A new look at residential electricity demand using household expenditure data," International Journal of Industrial Organization, 2014, 33, 37 - 47.

Goldberg, Linda S and José Manuel Campa, "The Sensitivity of the CPI to Exchange Rates: Distribution Margins, Imported Inputs, and Trade Exposure," The Review of Economics and Statistics, 2010, 92 (2), 392-407.

Goldberg, Pinelopi Koujianou and Michael M. Knetter, "Goods Prices and Exchange Rates: What Have We Learned?," Journal of Economic Literature, September 1997, 35 (3), 1243-1272.

Hausman, Catherine and Ryan Kellogg, "Welfare and Distributional Implications of Shale Gas," Brookings Papers on Economic Activity, 2015.

Hortacsu, Ali and Steven L. Puller, "Understanding strategic bidding in multi-unit auctions: a case study of the Texas electricity spot market," The RAND Journal of Economics, 2008, 39 (1), 86-114. 
Jha, Akshaya, "Dynamic Regulatory Distortions: Coal Procurement at U.S. Power Plants," Working Paper, 2015.

_ and Nick Muller, "The Environmental Consequences of Economic Regulation: Coal Procurement at the U.S. Power Plants," Working Paper, 2016.

Joskow, Paul L, "Contract duration and relationship-specific investments: Empirical evidence from coal markets," The American Economic Review, 1987, pp. 168-185.

Kilian, Lutz and Robert Vigfusson, "Pitfalls in estimating asymmetric effects of energy price shocks," International Finance Discussion Papers 970, Board of Governors of the Federal Reserve System (U.S.) May 2009.

Kim, Donghun and Ronald W. Cotterill, "Cost Pass-Through In Differentiated Product Markets: The Case Of U.S. Processed Cheese," The Journal of Industrial Economics, 2008, 56 (1), 32-48.

Knittel, Christopher R., Ben S. Meiselman, and James H. Stock, "The Pass-Through of RIN Prices to Wholesale and Retail Fuels under the Renewable Fuel Standard," Working Paper 21343, National Bureau of Economic Research July 2015.

_ , Konstantinos Metaxoglou, and Andre Trindade, "Natural Gas Prices and Coal Displacement: Evidence from Electricity Markets," Working Paper 21627, National Bureau of Economic Research October 2015.

Kolstad, Charles D and Frank A Wolak Jr, "Competition in interregional taxation: the case of western coal," The Journal of Political Economy, 1983, pp. 443-460.

Mansur, Erin T., "Upstream Competition and Vertical Integration in Electricity Markets," Journal of Law and Economics, February 2007, 50 (1), 125-56.

Maria, Corrado Di, Ian Lange, and Edwin van der Werf, "Should we be worried about the green paradox? Announcement effects of the Acid Rain Program," European Economic Review, 2014, 69, 143 162. Sustainability and Climate Change: From Theory to Pragmatic Policy.

Marion, Justin and Erich Muehlegger, "Fuel tax incidence and supply conditions," Journal of Public Economics, October 2011, 95 (9-10), 1202-1212.

Masten, Scott E and Keith J Crocker, "Efficient adaptation in long-term contracts: Take-or-pay provisions for natural gas," The American Economic Review, 1985, 75 (5), 1083-1093. 
Matisoff, Daniel C, Douglas S Noonan, and Jinshu Cui, "Electric Utilities, Fuel Use, and Responsiveness to Fuel Prices," Energy Economics, 2014, 46, 445-452.

Mokinski, Frieder and Nikolas M. Wölfing, "The effect of regulatory scrutiny: Asymmetric cost passthrough in power wholesale and its end," Journal of Regulatory Economics, 2014, 45 (2), 175-193.

Nakamura, Emi and Dawit Zerom, "Accounting for Incomplete Pass-through," The Review of Economic Studies, 2010, 77 (3), 1192-1230.

OECD/IEA, "Coal to Gas Competition in the U.S.," Technical Report, OECD/IEA 2013.

Peltzman, Sam, "Prices rise faster than they fall," Journal of Political Economy, 2000, 108 (3), 466-502.

Petrash, Jeffrey M, "Long-term Natural Gas Contracts: Dead, Dying, or merely Resting," Energy Law Journal, 2006, 27, 545 .

Verboven, Frank and Theon van Dijk, "Cartel Damages Claims and the Passing-on Defense," Journal of Industrial Economics, 09 2009, 57 (3), 457-491.

Weyl, E. Glen and Michal Fabinger, "Pass-Through as an Economic Tool: Principles of Incidence under Imperfect Competition," Journal of Political Economy, 2013, 121 (3), 528 - 583.

Wolfram, Catherine D., "Strategic Bidding in a Multiunit Auction: An Empirical Analysis of Bids to Supply Electricity in England and Wales," RAND Journal of Economics, Winter 1998, 29 (4), 703-725.

_. "Measuring duopoly power in the British electricity spot market," American Economic Review, 1999, pp. 805-826.

Wooldridge, Jeffrey M, Econometric Analysis of Cross Section and Panel Data, MIT press, 2010.

Zachmann, Georg and Christian Von Hirschhausen, "First Evidence of Asymmetric Cost Passthrough of EU Emissions Allowances: Examining Wholesale Electricity Prices in Germany," Economics Letters, 2008, 99 (3), 465-469. 